\title{
The Tango in Translation: Intertextuality, Filmic Representation, and Performing Argentine Tango in the United States
}

\author{
Emily J. McManus \\ Texas A\&M University
}

\section{Introduction}

Throughout the $20^{\text {th }}$ and into the $21^{\text {st }}$ century, the Argentine tango has been the subject of a wide variety of theatrical productions, silent and Hollywood movies, drawn and digitally animated cartoons, paintings and photographs, and print and television advertisements. It has been appropriated as a symbolic representation of the lower class, of violence, and of prostitution, as well as of upper-class cultural elitism, sensuality, and economic status. The tango has been mocked and satirized, sensationalized and caricaturized. It has been presented in its most basic form and its most flamboyant, as improvised Argentine tango or stylized and choreographed European ballroom tango. ${ }^{1}$

At the core of these representations are references to a sensationalized heterosexuality, often articulated through romanticized language and performed through revealing costumes and exaggerated eroticism. If not performed by Latin Americans, dancers are Latinized through stereotypical clothing and accessories or dyed hair and artificially tanned skin. Thus "passion" and "seduction" are central components of how the tango has been represented to the American public since the early twentieth century. Such representations emerge from what Tejaswini Niranjana refers to as a process of "cultural translation," in which elements of one culture are consciously or unconsciously re-articulated, even re-constructed, by an outside translator (Niranjana 3-4). When cultural translation occurs between a hegemonic culture and a marginalized culture, problematic stereotypes are perpetuated to create what Said Faiq refers to as a racialized "master discourse" (Faiq 6). Representations of the tango in the United States both create and reinforce a master discourse that inextricably ties the tango to an exoticized and eroticized Latin "Other."

\footnotetext{
${ }^{1}$ For more information on categorization of tango sub-genres, see Jo Baim, Tango: Creation of a Cultural Icon (Bloomington, IN: Indiana University Press, 2007) andRamón Pelinski. El tango nómade: ensayos sobre la diaspora del tango (Buenos Aires: Corregidor, 2000).
} 
Yet the tango is rarely separated from the status afforded to it through its association with Europe. Never considered fully legitimate by the Argentines until the French restylized the genre in the 1910s (Goertzen and Azzi 68), the same stereotypical and sexualized depictions of the tango just discussed frequently take place within an affluent ballroom or in a ritzy hotel dining room. The tango is simultaneously represented as Latin American and European, lower and upper class, brothel and ballroom, unsophisticated and dignified, overtly sexual and subtly sensual, instinct and aesthetic, body and mind. These seemingly contradictory characteristics are juxtaposed within media productions through the simultaneous performance of Latin American and European cultural symbols that have been adapted to conform to North American preconceptions and biases.

From the selection of actors to the musical soundtrack, U.S. filmic representations of the tango remain in constant dialogue with stereotypes surrounding Latin American and European cultural products throughout the twentieth century. The wide-spread appeal, potency, and longevity of such representations results from the simultaneous portrayal of the tango as both a sexualized and exoticized foreign cultural product and a symbol of perceived European cultural, racial, and economic elitism. Furthermore, while a variety of scholars have analyzed filmic representations of the tango, none have discussed the ways in which filmic intertextuality continues to influence contemporary media representations of the tango throughout the United States. ${ }^{2}$ This is particularly relevant when considering the extent to which contemporary representations of the tango reinforce racial, gendered, and sexual prejudices emerging from the historically asymmetrical power relations between the United States and Latin America.

Drawing primarily from Julia Kristeva's foundational theory of intertext as a "mosaic of quotations," Farahzad argues that intertexuality in cultural translation is a fundamentally interpretive process that first decontextualizes a text by removing culturally specific references and then re-contextualizes the genre in ways that are immediately understandable to the receiving culture (Farahzad 127). The process of recontextualization makes the translated text intelligible and approachable to the receiving

2 A few of which include: Marta Savigliano, "Evita: The Globalization of a National Myth," Latin American Perspectives 24, no. 6 (1997): 156-172; Robert Farris Thompson, Tango: The Art History of Love (New York: Pantheon Books, 2005); Carlos G. Groppa, The Tango in the United States: A History (Jefferson: McFarland and Co, 2004). 
culture through the incorporation of familiar references. To Lawrence Venuti, the recontextualization of a translated text within a new system of cultural values results not only in a semantic loss, but also in the perpetuation of cultural misunderstandings, stereotypes, biases, and preconceptions (Venuti "Translation, Intertextuality, Interpretation" 172). A similar decontextualization and recontextualization occurs when tango is translated by the U.S. media. The result is a wide variety of what Venuti refers to as "adaptations," in this case translations that reinterpret Latin American and European cultural symbols according to North American ideas of propriety and modesty.

Translated adaptations are particularly powerful when employed within the context of film, as all dimensions of the adaptation form a complex layer of intertextual meaning. Stylistic characteristics, ranging from the musical soundtrack to costumes and cinematography to an actor's reputation, are interpreted according to the values and belief systems within the socio-cultural context that surrounds its reception (Venuti "Adaptation, Translation, Critique" 30). In instances in which the receiving culture's systems of signification and identification are articulated through a multidimensional medium, filmic adaptations of the tango are simultaneously able to create and reinforce Americanized interpretations of the music, movement, costumes, behavior, and etiquette. Filmic interpretations of the tango that emerged as early as 1921 thus became "intertexts" in Kristeva's original formulation, as they engage with past, present, and future representations through direct and indirect intertextual quotation while creating and reinforcing tango's highly racialized master discourse.

This is particularly significant considering the extent to which media representations inform performance practice among contemporary tango dancers, musicians, and deejays throughout the United States. The films discussed in this paper were selected specifically because of the frequency with which they were referenced by U.S. tanguera/os throughout the course of my ethnographic fieldwork with the Minneapolis, MN tango community and at tango festivals across the United States. While many of the U.S. tanguera/os that I worked with actively distance themselves from sensationalized representations of the tango, the underlying racial and gendered prejudices that such representations articulate remained largely unnoticed and rarely contested. Furthermore, the extent to which Americanized representation of the Argentine tango draw from exoticized Latin American stereotypes and representations of European elitism is 
increasingly relevant when understood in dialogue with U.S. tanguera/os who, while often attracted to the genre because of the sexuality it represents, frequently explain their ongoing participation by discussing their individual identification with the tango because of its European influences. As the most visible and approachable translations of the tango, the dual representations of Latin American and European cultural stereotypes perpetuated by the U.S. media are unknowingly embodied and rearticulated in contemporary practice and have a very real effect on the construction of a primarily Anglo-American, heterosexual, and heteronormative U.S. tango community.

\section{Filmic Representations of the Tango}

\section{Four Horsemen of the Apocalypse (1921)}

The tango featured in Four Horsemen of the Apocalypse, released in 1921 by Metro Pictures Corporation, is both the first adaption of tango by the U.S. media and its most iconic representation to date. Set in a raucous bar intended to evoke La Boca district of Buenos Aires, Julio (Rudolf Valentino) and his elderly grandfather are depicted watching from the sidelines as a young dance couple walks onto the dance floor and is introduced to the crowded bar. Immediately noticeable is the stark contrast between the presumably Spanish dancers and their Argentine audience, here established through the manipulation of stereotypical costumes and behaviors. The leader, for example, is dressed in a highwaist tuxedo while the follower wears a 1920s flapper dress, Manila shawl, and a carnation in her bobbed dark hair. Their highly stylized clothing and posh and distanced demeanor is juxtaposed with the ponchos, cowboy hats, and boots worn by the Argentine "gauchos" (cowboys) engaged in excessive debauchery, gambling, and womanizing.

Although partaking in his own flirtatious conversation with a woman at his table, Julio cannot help but be distracted by the tango being performed on the dance floor. When combined with their stereotypical Spanish clothing, the couple's employment of an open waltz-style embrace evokes an association with the European ballroom tango that was first adapted by Parisians and quickly migrated throughout Europe (Baim 4986). In order to conform to European and North American ideas of modesty, the Argentine "close embrace" (characterized by the complete touching of torsos) was modified to incorporate physical space between dance partners (Baim 69). The "open 
embrace" style used by the Spanish dance couple immediately positions their performance as culturally foreign within its La Boca setting and thus attracts the critical attention of Julio. From the perspective of the North American audience, however, the use of a European open embrace immediately positions the tango as an elite, modest, European cultural product within a setting that perpetuates stereotypes of Latin Americans as poor and prone to impropriety. Associations between the tango and its purported birth in the Argentine brothels are also maintained, even as the movement itself is legitimized through European intervention. As a result, the dance remains accessible to North American practitioners without limiting its exotic appeal.

The mixed reference to Argentine and European influences on the tango is, of course, a byproduct of the transnational interaction between the two. When understood according to a process of cultural translation and adaptation, it is not surprising that an American film company would choose to foreground the Europeanized aspects of the genre in order to make it approachable and comprehensible to viewers. Yet the film itself is simultaneously participating in a dual process of cultural translation that evokes and perpetuates Latin American and European cultural stereotypes. Because both are relatively unfamiliar to North Americans, the film must be adapted to conform to stylistic adaptions popularized throughout the United States. Perhaps the most interesting way this film does so is through frequent incorporation of the promenade embrace (a v-shaped embrace) popularized by U.S. dance teachers Irene and Vernon Castle in their tango teas and 1914 dance manual, Modern Dancing. ${ }^{3}$ By adding the promenade embrace into the opening tango performance, the movement becomes immediately recognizable to the thousands of North Americans who participated in the tango craze of the 1910s/1920s.

Although the Americanization goes unrecognized within the film itself, Julio expresses his displeasure with the purportedly European ballroom tango by intervening in the performance and initiating what the viewer assumes to be an authentic Argentine tango. Reassuring the American public of Julio's credibility as conveyer of cultural

\footnotetext{
3 Although the promenade embrace is sometimes used in Argentine tango, it was popularized by the Castles during their attempt to simplify and standardize the Argentine tango for an American audience. The promenade was featured in their dance manual and was commonly performed at tango teas. For more information on the Castles, tango teas, and dance manuals from 1910s/1920s see Jo Baim, Tango: Creation of a Cultural Icon, 49-86.
} 
knowledge is his familiarity with the La Boca bar, his exaggerated gaucho costume complete with chaps, boots, and spurs, and his use of the Argentine "close embrace."

Represented through well-known stereotypical visual signifiers of Argentina generally, and tango more specifically, Julio's dance is partially indicative of what Venuti terms "interrogative translations," in which the viewer is led to evaluate, question, or resist cultural translations (Venuti "Translation, Intertextuality, Interpretation" 165). Here the viewer assumes Julio is confronting European adaptations of the genre to assert a presumably authentic original. This is reinforced by Julio's immediate interest in and disdain for the European dancers, his direct confrontation of them, and his eventually successful seduction of the female follower. Yet still we see the incorporation of the same promenade embrace used by the Europeans in the opening dance, albeit within the Argentine close-embrace style. While interpreted by the North American viewers as a true or "authentic" Argentine tango, Julio's dance continues to foreground the North American movement adaptations that are immediately accessible to the viewer.

Additionally, while the viewer assumes Julio's performance is emblematic of an Argentine-style tango, it remains firmly positioned within U.S. cultural stereotypes and prejudices about Latin America. Julio is a drunk, macho, womanizer whose actions are depicted as aggressively impulsive. At the same time, Julio is a skilled dancer whose movements are interpreted (at least by the follower) as sexually provocative and enticing, thus conforming to the hegemonic tendency of colonial powers to feminize and sexualize the marginalized "Other." The result is an interpretive adaptation of the tango that engages with past, present, and future preconceptions and representations of the tango in a non-linear process of intertextual identification. It is here that the exaggerated promenade embrace, for instance, was tied to popular representations of the Argentine tango and European ballroom tango tradition. The dramatic kiss that concludes Valentino's tango and his subsequent "heartthrob" popularity further perpetuate North American representations of an eroticized Latin "Other," while costumes and behavior articulate racialized stereotypes.

\section{Some Like it Hot (1959)}

Although also drawing from the racial stereotypes articulated in Four Horsemen of the Apocalypse, the tango performed within Billy Wilder's Some Like it Hot (1959) achieves its 
significance primarily because of its engagement with a much larger narrative of acceptable and unacceptable displays of sexuality. The parodies and satire employed throughout Some Like it Hot can thus be understood as representative of 1950s attitudes towards sexuality in the United States, and in particular the sanctioning of heterosexual desire alongside the implicit rejection of homosexuality. Starring Marilyn Monroe, Tony Curtis, and Jack Lemmon, Some Like it Hot is set in Chicago in 1929 and tells the story of two unemployed musicians (Joe and Jerry). Not only are Joe and Jerry in need of a job, they must also find a way to evade the mob. The two quickly devise a plan to dress as women and audition for an all-female orchestra. Their plan is successful but shortsighted, as Joe and Jerry immediately realize that they must now maintain their drag costuming to hide their identities. Their commitment to doing so, however, wavers considerably when each is confronted with a potential romantic partner. Joe's resolve immediately dissolves when he is approached by the beautiful Sugar Kane Kowalczyk (Marilyn Monroe); however, Jerry continues his performance as "Daphne" even when courted by the short and slightly nerdy millionaire Osgood Fielding III.

As soon as Joe removes his drag and begins his romantic encounter with Sugar Kane Kowalczyk, Some Like it Hot juxtaposes an erotic heterosexual encounter with a parody of same-sex tango in drag costuming. This juxtaposition occurs through a cinematographic cutting between a topless Sugar Kane attempting to "cure" Joe of his alleged impotency and Daphne and Osgood's comedic tango in exaggerated drag. Wearing a costume similar to that worn by Rudolf Valentino's follower, Daphne (Jerry) performs in a 1920s flapper dress, Manila shawl, and bobbed wig, while holding a carnation. His drag is not very convincing, however, as his physical stature is substantially larger than that of Osgood. Additionally, they perform to the emblematic La Cumparsita, here performed diegetically by the house band. Written by Gerardo Matos Rodríguez and arranged for tango orchestra by Roberto Firpo, "La Cumparsita" achieved its international notoriety in 1916 and has since served as one of the most recognizable sonic symbols of the Argentine tango.

Drawing on the same cultural stereotypes articulated through Julio's tango, Some Like It Hot uses generic Spanish and Latin American stereotypes alongside a sonic evocation of Argentina to position the tango as inextricably foreign. Not surprisingly, the tango that follows is more emblematic of that performed in Four Horsemen of the Apocalypse than 
a traditional Argentine tango. Although thoroughly Americanized, the use of cultural stereotypes alongside a highly exaggerated promenade embrace and pseudo-flamenco stylization mocks the genre while exoticizing, feminizing, and sexualizing its performers. Thus the dance concludes with Osgood wrapping a shawl around his waist, Jerry placing a carnation between his lips, and the musicians shouting an enthusiastic "Olé!"

In many ways, the slapstick comedy and unconvincing drag present a stark contrast to the tango performed in Four Horsemen of the Apocalypse. Contrary to the widespread popularity afforded to Valentino as Latinized "heartthrob," in Some Like it Hot the tango and its same-sex performers are mocked, satirized, and dismissed as ridiculous and over the top. Much like the 1921 rendition, however, the tango in Some Like it Hot intertextually references the same Spanish stereotypes (the carnation, Manila shawl, and flamenco) and Latin American stereotypes (the tango's promenade embrace, and the musicians shouting “Olé!) performed by Valentino. While the tango in Four Horsemen of the Apocalypse appealed to a U.S. public experiencing the large-scale tango craze of the 1910s/20s, by the 1950s the tango has lost its widespread appeal. It did, however, remain explicitly linked with sexuality, an association clearly evoked within Some Like it Hot. Frequent scene changes between the two couples reinforce this association by featuring a half-naked Marilyn Monroe engaged in an intimate heterosexual act. Arguably the most highly sexualized actress of her generation, Marilyn Monroe's performance is provocative and risqué, but representative of an acceptable display of heterosexuality. On the other hand, by juxtaposing Monroe's sexual intimacy with a satirized same-sex tango, the viewer is left with the impression that tango is also representative of perceived sexual deviance. The tango specifically, and Latin America more generally, are thus associated with explicit and unrestrained sexual intimacy, as well as the presumably problematic possibility of male homosexuality.

\section{Last Tango in Paris (1972)}

Overtly sexualized representations of the tango in the United States are further satirized in Bernardo Bertolucci's 1972 film, Last Tango in Paris (Ultimo tango a Parigi). Starring Marlon Brando and Maria Schneider, Last Tango in Paris is infamous for its explicit, sometimes considered to be pornographic, sex scenes. Although public reception of the film was fraught with controversy, many film critics praised Last Tango in Paris as "one of the great emotional experiences of our time" (Ebert). As a result, the film was the 
subject of a cover story in Time and was lauded for its "boldness and brutality" (Time.com). Similarly positive reviews appeared in Newsweek and The New Yorker, the latter of which applauded Last Tango in Paris as the "most powerfully erotic movie ever made" (Kael). The emphasis placed by these reviews on sexuality, experimentation, eroticism, and brutality are representative of the ways in which the movie was received by critics and the public alike.

Documenting the affair between a middle-aged man (Paul) and an anonymous younger woman engaged to be married, Last Tango in Paris confronts a wide variety of sexual taboos that range from masturbation to implied bestiality. Although the majority of the film focuses on the couple's sexual experimentation, the tango is satirized and caricatured during the violent disintegration of their relationship. Towards the end of the film, Paul decides to end the affair by vanishing from their mutual apartment complex. Time passes and the two later meet coincidently on the street and begin to discuss their failed relationship. Paul invites the younger woman to continue the conversation at an elegant café located in a hotel ballroom. A tango competition provides the backdrop to their awkward and distant conversation and the camera frequently pans across a dozen or so couples on the dance floor. Immediately noticeable is the absence of Latin American signifiers in the performance, as the Argentine tango has here been completely replaced by its European variant. The incorporation of European ballroom tango is not surprising given the title and setting of the film in Paris, as well as its European director and North American premier. Additionally, Last Tango in Paris lacks the overt caricatures of Latin America frequently incorporated in earlier films. The women, for instance, wear short 1960s cocktail dresses and expressionless faces while they dance with formally suited male partners.

Although avoiding national or cultural stereotypes, Bertolucci focuses heavily on associations between the tango and economic and cultural elitism. Upon arrival, Paul performs his position of privilege by clapping his hands, summoning the "Garçon," and ordering the younger woman a glass of champagne. As he does so, the camera spans to the dancers on the floor, seriously performing the same promenade embrace mocked in Some Like it Hot. Although resonating with previous filmic representations of the tango, the use of the promenade embrace is here indicative of the extent to which it has been fully integrated into the European ballroom tradition. 
After catching a glimpse of the ongoing tango competition, Paul attempts to persuade his former lover to resume their affair. Previously built entirely on sexual attraction, Paul hopes to restore the relationship by finally revealing his name to the younger woman and telling her his life story. The lack of anonymity leaves the woman wholly uninterested and increasingly agitated. They continue, however, to indulge in the champagne and quickly become intoxicated. Upon their departure from the hotel, Paul ignores the structured formality of the tango competition and persuades his former lover to interrupt the performance with their own rendition of the tango. The dance that follows consists mostly of falling to the ground, laughing, and rolling around on the floor between the competing couples. They further infuriate the judges and contestants when their sporadic dance ends with an erotic kiss positioned directly in front of the judges' table. The fury displayed by the judges as they physically remove the couple from the dance floor is met with a defiant Paul mooning all in attendance.

Although Paul and his lover mock the tango through their disruptive performance, the ways in which they do so are significantly different from those presented in Some Like it Hot. Not only does the movie make no connection between the tango and Latin America, their movement implies no direct knowledge of the tango specifically or social dance more generally. The tango is thus represented as an esoteric art form, known only by upper-class professionally trained ballroom dancers. Their interpretation of the movement and disregard for the rules and conventions of the competition suggest that they dismiss the tango as culturally irrelevant. Additionally, the highly sexualized nature of this film and the importance placed on the tango (included in the title) strongly resonate with previous stereotypes equating the tango with heterosexual desire. The quick decline of the affair between Paul and the younger woman, however, culminates directly after their performance of the tango and escalates to Paul's murder at the hands of his lover. Bertolucci's most radical interrogative adaptation of the genre, consequently, is his alignment of the tango with an extreme and perverse sexuality inevitably negotiated through brutality and violence.

\section{The Scent of a Woman (1992)}

It was not until the 1992 release of Universal Studio's The Scent of a Woman that filmic representations of the tango moved away from the parody and satire evoked in previous decades. Furthermore, it was the first time since Four Horsemen of the Apocalypse that the 
Argentine tango, rather than ballroom tango, was featured. The sudden shift in attitude afforded to the tango in this film is undoubtedly the result of renewed interest in the Argentine tango from the popularity and longevity of the theatrical productions Tango Argentino (premiered in 1985) and Forever Tango (premiered in 1990). ${ }^{4}$ Although choreographed theatrical productions, these shows re-introduced the American public to the improvisatory Argentine tango typically performed at evening social dances called "milongas." Those with little prior knowledge of the tango were now able to differentiate between the popular representations of highly stylized and choreographed ballroom dance and the improvisatory movement of the Argentine tango.

Starring Al Pacino (Colonel Frank Slade) and Chris O'Donnell (Charlie), The Scent of a Woman tells the story of a young college student (Charlie) who takes a weekend job as caregiver to the blind and suicidal Colonel Slade. Slade insists that they spend their weekend in New York City and the two find themselves at a ritzy restaurant where waiters dress in tuxedos, high ceilings are adorned with chandeliers, and a small dance floor features a tango orchestra. Slade asks Charlie to describe who is in attendance, and Charlie tells him about a beautiful young woman seated at the neighboring table. After introducing himself, Slade learns that her name is Donna and invites her to tango. As they walk onto the dance floor the orchestra sounds the first notes of Carlos Gardel's 1935 "Por una Cabeza."

The orchestra's performance of "Por una Cabeza" rather than "La Cumparsita" is only one of the many ways The Scent of a Woman avoids the well-known and frequently mocked associations that emerged in previous films. Although both pieces were immediately popular in Argentina after their original composition, "Por una Cabeza" lacks the clichéd and parodic associations of previous filmic quotation. As a result, it remains relatively unknown to the American public and is most recognizable to established tango aficionados. ${ }^{5}$ Additionally, the style of dance departs significantly from

\footnotetext{
${ }^{4}$ For more information on Tango Argentino and Forever Tango see Groppa 2004, 173-176; and Thompson 2005, 265-271. For more information on the global impact of these shows, see Savigliano1995, 191-202. Available audio recordings of Tango Argentino include: Claudio Segovia \& Hector Orezzoli, 1986, Tango Argentino, Original Cast Recording Vol. I and II (CD), Atlantic; and Claudio Segovia \& Hector Orezzoli, 1986, Tango Argentino - 2 Record Set (LP), Atlantic. A video recording is available of Forever Tango: Luis Bravo. 2008. Forever Tango: Live from Teatro Coliseo Podesta (DVD). Dptv Media.

${ }^{5}$ Scholars and musicians in Argentina and across the globe are in the process of locating, transcribing, cataloging, and publishing a comprehensive collection of tango scores. Since a comprehensive collection
} 
the overly Americanized, sensationalized, or mocked renditions frequently portrayed in films. Slade leads Donna in an improvised and close-embrace tango that lacks the exaggerated ornaments and promenade embrace popular in other films. Much like how the tango is performed at an Argentine milonga, their movements remain relatively small and understated, particularly in the opening A section of the piece. Even as the music switches from the thinly textured A section, performed pianissimo by the violins, to a fully orchestrated fortissimo in the B section, the couple only accentuates the increasingly dramatic music with a few timid dips and small ornaments common to a milonga setting.

The lack of an exaggerated promenade embrace and the incorporation of traditional Argentine ornamentation are the primary reasons why many of the tanguera/os with which I conducted fieldwork applauded The Scent of a Woman as the first movie to represent an "authentic" Argentine tango to American audiences. Not only does the performance depart from overly sensationalized representations of the genre, it distances itself entirely from European and American interpretations of the movement and music. Additionally, the reframing that took place was seen as particularly important after what many of my informants believed to be the tango's moral degradation in Last Tango in Paris. For these reasons, the tango scene in The Scent of a Woman was often recommended to those new to our tango classes or used to entice interest among non-tanguera/o friends.

Although offering a more accurate stylistic depiction of the Argentine tango, The Scent of a Woman resonates intertextually with earlier films, particularly in the ways in which its adaptation is laden with racialized and sexualized stereotypes surrounding the tango and its performers. The elite, wealthy, and predominantly Anglo-American restaurant patrons are juxtaposed with the dark features of the tango orchestra, the Mediterranean features of Italian-American Al Pacino, and the darkening of Gabrielle Anwar's hair and eye pigmentation. Furthermore, the scene immediately following their tango begins with a limousine driver arranging a meeting between Slade and a prostitute. As a result, the

does not currently exist, musicians must necessarily transcribe scores from historic recordings. Although a huge variety of audio anthologies have been released, many highlight the classical performances of Astor Piazzolla rather than the dance music performed by tango orchestras. A variety of online resources are available for dancers and musicians interested in collecting tango recordings suitable for dancing. Examples include: www.tangodj.org; www.todotang.com; and www.zivals.com. 
association between tango and sexuality is maintained, albeit refined and sensual rather than perverse or violent. Although physically and sonically evoking an Argentine cultural product, the refined sensuality and sophisticated ballroom setting in which their tango takes place echoes the early-twentieth century tendency to legitimize the Argentine tango through European intervention.

\section{Tango in Less Prominent Films and Television Advertisements}

Whether through the setting of the performance or the selection of actors, many films released after the 1992 premier of The Scent of a Woman also foreground the tango's Argentine heritage while simultaneously evoking the genre's European influences. Although most focus on the Argentine tango rather than the European ballroom tango, the maintenance of this dichotomy continues to perpetuate racialized stereotypes of an exotic and sexualized Latin American "Other." Eva Perón (Madonna) and Che (Antonio Banderas) in Evita (1998), for instance, conflate the Latin American and European heritage of the genre (and the subsequent identification with lower and upper classes respectively) by performing a tango/waltz fusion to Andrew Lloyd Webber's "Waltz for Eva and Che." Not only does the setting switch between a ballroom and a butcher shop, the tango is performed by two of the most recognizable sex symbols of the 1990s - a blond Madonna and Spanish Banderas. Later movies, such as Take the Lead (New Line Cinema 2006), featuring Antonio Banderas and Katya Virshilas, and Shall we Dance (Miramax Films, 2004), featuring Richard Gere and Jennifer Lopez, typically incorporate a well-known Latin American, Hispanic, or Spanish actor. Not only do their accents, costumes, dark hair, facial features, and sexualized bodies resonate with essentializing preconceptions of Latin Americans, they are frequently juxtaposed with stereotypical representations of Anglo-Americans. Regardless of the actual ethnic heritage of the actor (for example, Madonna's Italian American heritage), the partners of well-known Hispanic actors are frequently Anglicized through noticeably lighter complexions, hair, or eye color.

Within most such representations, the Latinized performer generally functions as both the teacher and/or leader of the dance and the amorous seducer. When merged with the romanticized and/or sexualized settings of their performance, the enactment of racialized stereotypes reinforces problematic representations of the sexualized Latin "Other," albeit positioned within the safe familiarity of whiteness. Given the frequency 
of sexualized stereotypes, it is not surprising that similar associations are evoked by advertisements hoping to capitalize on the tango's Latin American exoticism and heterosexual eroticism. During the period of my research, for example, many retail stores such as Banana Republic Inc. and J. Crew have incorporated tango on their corporate playlists. In these instances soundtracks draw heavily from "nuevo-tango" bands such as the electronica/hip-hop/tango fusions of Gotan Project and Bajofondo. The result is a sonic soundscape that suggests that their merchandise is classy, sophisticated, sexy and exotic, and simultaneously young, fresh, current, and hip. The tango also makes frequent appearances on television advertisements, either through aural references or visual signifiers. One example of the latter is a recent commercial for a mattress company that features a young couple horizontally mimicking the movement of the tango on a mattress and capitalizing on the common trope that tango "is the vertical expression of a horizontal desire" (Sleepy's Mattress Commercial).

Far more explicit, however, is the use of tango in Viagra's promotion of its medication to correct erectile dysfunction. Included as part of their "Viva Viagra!" campaign, this commercial begins with a middle-aged Anglo-American couple mundanely sitting on the couch and watching television. The camera zooms in to show a smile creeping onto the man's face as a generic Latin rhythm starts playing in the background. The couple throws the remote-control out the window, dramatically enters a promenade embrace, and tangos into the bedroom while the narrator instructs the viewer that, "Once you've dealt with the things that come between you, don't let erectile dysfunction get in the way!" (Viva Viagra).

\section{Conclusions and Larger Implications}

Such representations are indicative of a process of translation in which an exoticized cultural product is adapted in order to be approachable and understandable to a North American audience. Through this process of translation, intertextual quotations perpetuate well-known preconceptions and prejudices surrounding the genre. It is precisely because of these highly sexualized media representations that the tango has come to inhabit the position it does in $21^{\text {st }}$ century North American culture. Its cinematic representations and more recent commodification all position the highly exaggerated and sexualized Latin "Other" against stereotypes of a sophisticated European elite. From the early twentieth century, the tango has been translated to the North American public in 
ways that reinforce power relations between the United States and post-colonial Argentina and conform to existing prejudices. Once canonized, such representations are referenced in subsequent films, a process which ultimately propels and reinforces cultural stereotypes. The result is a master discourse that works to construct the genre within the eyes of the general public and inevitably informs performances of tango in the United States today.

As the most visible contributor to the master discourse surrounding the tango in the United States, these films and media depictions shape the ways U.S. tanguera/os interact with the genre. Although a significant number of participants will later move on to distance themselves from such representations, it is important to remember that these same stereotypes formed the basis of their knowledge of the tango prior to involvement. The ways in which U.S. tanguera/os embody or contest such stereotypes, furthermore, corresponds to ideas of authenticity that have been constructed vis-à-vis media representations and other forms of translated discourse, including a wide variety of popular and scholarly histories.

The U.S. tanguera/os I conducted ethnographic fieldwork with, for example, understood the tango to be both foreign and exotic, characteristics which implicitly sanctioned the performance of sexuality within a puritanical United States. Yet many also felt a strong ethnic relationship with the tango as a result of the genres' hybrid colonial history and twentieth-century transnational influences. Participants, for example, strongly associated the tango with its European influences, while disregarding, downplaying, or denying the well-established influence of the Afro-Argentine. In particular, tanguera/os emphasize the tango's two primary European influences: the musical influences emerging out of late-nineteenth century Spanish and Italian immigration to Argentina; and the process of exportation, stylization, and importation that occurred between Argentina and Paris during the first half of the twentieth century. ${ }^{6}$ Although it is the overly sexualized Latin-ness that often draws participants to the genre, their personal involvement is qualified (and hence legitimized) by emphasizing the role of Europe in popularizing the genre.

${ }^{6}$ For more information about immigration in Argentina and its relationship to the tango, see: Donna J. Guy, Sex and Danger in Buenos Aires: Prostitution, Family, and Nation in Argentina (Lincoln: University of Nebraska Press, 1991). For more information on international interaction with the tango, see: Marta Savigliano, Tango and the Political Economy of Passion (Boulder: Westview Press, Inc., 1995). 
This relationship is further complicated by the fact that many of the U.S. tanguera/os I worked with disassociated Argentina from Latin America more generally. One tanguero informed me, for example, that "the thing is, Argentina is not considered Latin America. They speak Spanish, but they consider themselves Europeans."” Such associations are reinforced through reference to late nineteenth and early twentiethcentury Argentine scholars, many of whom propagated Eurocentric historical narratives that foreground European influences while excluding Afro-Argentine influences. ${ }^{8}$ While the results of this exclusionary history are numerous, Eurocentric historical accounts of the origin and development of the tango strongly resonate with U.S. tanguera/os, 80\% of which identified as Anglo-American or Caucasian in an online survey administered during my fieldwork. ${ }^{9}$ For example, one Anglo-American tanguero informed me that "had my family got on a different boat, I could be an Argentine." 10 Eurocentric representations of the tango both enable and reinforce individual identification with the genre, in that they allow U.S. tanguera/os to imagine a direct ethnic link with the tango based on shared European heritage.

Similar processes of individual identification vis-à-vis a shared European heritage were commonly expressed to me and implicitly sanctioned and/or justified participation of Anglo-American tanguera/os within a foreign cultural tradition. Additionally, the exoticization and eroticization of the tango in filmic representations are frequently reinforced by U.S. tanguera/os through common tropes which suggest, for example, that the tango is a "three minute love affair." Not surprisingly, among the U.S. tanguera/os I surveyed, 87\% identified as heterosexual. Furthermore, when discussing gender roles within the tango, many of my informants foregrounded highly heteronormative roles characterized by an active male leader and a (re)active female follower.

\footnotetext{
${ }^{7}$ Anonymous. Phone interview by author. Audio recording. 26 March 2010.

8 For more information see: Marta Savigliano Tango and the Political Economy of Passion (Boulder, CO: Westview Press, Inc., 1995); Julie Taylor, Paper Tangos (Durham and London: Duke University Press, 1998); John Charles Chasteen, "Black Kings, Blackface Carnival, and Nineteenth-Century Origins of the Tango," in Latin American Popular Culture: An Introduction, Eds. William H Beezley, Linda Curci0-Nagy, and Linda Ann Curcio (Delaware: Scholarly Resources Inc., 2000), 43-60; Robert Farris Thompson, Tango: The Art History of Love (New York: Pantheon Books, 2005); Claire Healy, "Review Essay: Afro-Argentine Historiography," Atlantic Studies 3, no 1 (2006): 111-120.

${ }^{9}$ Online Survey, April 14, 2010. Administered by email to dance instructors in Portland, Seattle, San Francisco, Los Angeles, Chicago, Minneapolis, Kansas City, Houston, Austin, Miami, New York, Boston, and Providence. 290 responses received.

${ }^{10}$ Anonymous 2. Informal interview by author. Recorded in field notes. 20 May 2008.
} 
Although the foregrounding of a Eurocentric and heteronormative tango by U.S. tanguera/os represents a seemingly harmless attempt to perform individual identity, on a much larger level these tendencies reinforce the same problematic representations of the tango discussed throughout this paper. The ongoing sexualization of the tango is thus articulated alongside a long history of colonial and post-colonial racial stereotypes, while the foregrounding of European influences perpetuates the historic and contemporary exclusion of Afro-Argentines from tango historiography. Furthermore, when articulated by U.S. tanguera/os, the foregrounding of European influences on the tango results in the creation of a homogenized tango community that implicitly excludes contemporary participants who fall outside of the tango's Eurocentric and heteronormative master discourse. While all of the tanguera/os with whom I worked articulated an explicitly inclusive ideology, many also expressed concern about low retention rates in tango classes as a result of the exclusionary environment present in many tango communities. In order to remedy this incongruity, both in theory and in practice, it is necessary to evaluate the ways in which a century of problematic representations of the tango by the U.S. media are functioning intertextually with contemporary performance practice. Analyses of tango in film, consequently, must move beyond an attempt to classify filmic representations as "authentic" or "inauthentic" and European ballroom tango or Argentine tango, and must instead investigate the underlying prejudices articulated through the juxtaposition and translation of Latin American and European cultural stereotypes. 


\section{REFERENCES}

Baim, Jo.Tango: Creation of a Cultural Icon. Bloomington, IN: Indiana University Press, 2007.

Bravo, Luis. 2008. Forever Tango: Live from Teatro Coliseo Podesta (DVD). Dptv Media.

Chasteen, John Charles. "Black Kings, Blackface Carnival, and Nineteenth-Century Origins of the Tango." Latin American Popular Culture: An Introduction. Ed. William H Beezley, Linda Curcio-Nagy, and Linda Ann Curcio. Delaware: Scholarly Resources Inc., 2000: 43-60.

Ebert, Roger. "Last Tango in Paris." RogerEbert.com.14 October 1972. Web. 23 March 2010.

Faiq, Said. Trans-lated:Translation and Cultural Manipulation. New York and Toronto: University Press of America, Inc., 2007.

Farahzad, Farzaneh. "Translation as an Intertextual Practice.” Perspectives 16.3 (2008): 125-131.

Guy, Donna J. Sex and Danger in Buenos Aires: Prostitution, Family, and Nation in Argentina. Lincoln: University of Nebraska Press, 1991.

Goertzen, Chris and Maria Susana Azzi, "Globalization and the Tango." Yearbook for Traditional Music 13 (1999): 67-76.

Groppa, Carlos G. The Tango in the United States: A History. Jefferson: McFarland and Co, 2004.

Healy, Claire. "Review Essay: Afro-Argentine Historiography." Atlantic Studies 3.1 (2006): 111-120.

Kael, Pauline. "Last Tango in Paris.” New Yorker Magazine. Web. 23 March 2010. 
Kristeva, Julia. Desire in Language: A Semiotic Approach to Literature and Art. Trans. Thomas Gora, Alica Jardine, and Leon S. Roudiez. Ed. Leon S. Roudiez. New York: Columbia University Press, 1980.

Niranjana, Tejeswini. Sitting Translation: History, Post-Structuralism, and the Colonial Context. Berkeley, University of California Press, 1992.

Pelinski, Ramón. El tango nómade: ensayos sobre la diaspora del tango. Buenos Aires: Corregidor, 2000.

Savigliano, Marta. Tango and the Political Economy of Passion. Boulder: Westview Press, Inc., 1995.

------. "Evita: The Globalization of a National Myth." Latin American Perspectives 24.6 (1997): 156-172.

Segovia, Claudio\& Hector Orezzoli. 1986. Tango Argentino, Original Cast Recording Vol. I and II (CD). Atlantic

-----. 1986. Tango Argentino - 2 Record Set (LP). Sleepy's Mattress Commercial. “Tango.”Sleepy's Mattress. Web. 2 May 2010.

Taylor, Julie. Paper Tangos. Durham and London: Duke University Press, 1998.

Thompson, Robert Farris. Tango: The Art History of Love. New York: Pantheon Books, 2005.

Time.com, Author Unknown. "Self-Portrait of an Angel and Monster." Time Magazine.22 January 1973. Web. 23 March 2010.

Turino, Thomas. Nationalists, Cosmopolitans, and Popular Music in Zimbabwe. Chicago, University of Chicago Press, 2000.

Venuti, Lawrence. "Translation, Intertextuality, Interpretation." Romance Studies 27.3 (2009):157-173. 
Venuti, Lawrence. “Adaptation, Translation, Critique.” Journal of Visual Culture 6.25 (2007): 25-43.

Viva Viagra 2009 Advertising Campaign, “Tango” Viagra. Web. 2 May 2010. 